Frontiers: The Interdisciplinary Journal of Study Abroad

(C) 2020 Virginia B. Wickline et al.

The work is licensed under the Creative Commons Attribution-NonCommercial-

NoDerivatives 4.0 International License.

Volume 32, Issue 3, pp. 126-155

DOI 10.36366/frontiers.v32i3.582

FORUM

ON EDUCATION

ABROAD

\title{
Increasing Intercultural
}

Competence in Undergraduate

Education: Study Abroad is a

\section{Viable Way, but Not the Only Way}

Virginia B. (Ginger) Wickline ${ }^{1}$, Allie M. Shea ${ }^{2}$, Cheryl D.Young ${ }^{3}$, Deborah Wiese ${ }^{3}$

\begin{abstract}
Undergraduate students $(\mathrm{N}=1,261)$ at a Midwest, public doctoral institution completed intercultural competence (ICC) measures before/after study abroad or an on-campus global course (G-Course). We hypothesized that students in study abroad versus on-campus global courses would differ in ICC both before/after their global experience. We predicted that students would increase in ICC after study abroad or a G-course (compared to their own pre-scores). We hypothesized that students who did not intend to study abroad would be lower in ICC than those who intended to study abroad, who would be lower than study abroad students. Lastly, we predicted that students who engaged more often in globally related extracurricular and co-curricular activities would report higher ICC. The data fully or partially supported each hypothesis: highlighting myriad factors impacting university students' ICC scores both at home and abroad and revealing important differences between students who choose to study abroad and those who do not. Study abroad does appear to change some but not all aspects of ICC. A student self-selection bias might make ICC changes more difficult to document after study abroad programs. Moreover, on-campus
\end{abstract}

1 Georgia Southern University, Statesboro, GA, USA

2 INSTITUTE OF WORLD POLITICS, WASHINGTON, D.C., USA

3 MiAMI UNIVERSITY, OXFORD, OH, USA

Corresponding author: Virginia B. Wickline, Georgia Southern University, vwickline@georgiasouthern.edu 
activities are also related to ICC development for university students. When institutions of higher education are seeking to help develop ICC in their students, study abroad is not the only effective approach and should therefore be considered one important campus internationalization tool among many.

\section{Abstract in French}

Les étudiants de premier cycle $(\mathrm{N}=1261)$ dans un établissement doctoral public du Midwest ont suivi des mesures de compétence interculturelle (ICC) avant / après leurs études à l'étranger ou un cours global sur le campus (cours G). Nous avons émis I'hypothèse que les étudiants en études à l'étranger par rapport aux cours mondiaux sur le campus différeraient en ICC avant / après leur expérience globale. Nous avons prédit que les étudiants augmenteraient en ICC après des études à l'étranger ou un cours $\mathrm{G}$ (par rapport à leurs propres pré-scores). Nous avons émis I'hypothèse que les étudiants qui n'avaient pas l'intention d'étudier à l'étranger seraient plus bas en ICC que ceux qui avaient l'intention d'étudier à l'étranger, qui seraient inférieurs aux étudiants à l'étranger. Enfin, nous avons prédit que les étudiants qui s'engageaient plus souvent dans des activités parascolaires et parascolaires liées à l'échelle mondiale auraient un ICC plus élevé. Les données étayaient totalement ou partiellement chaque hypothèse: mettant en évidence une myriade de facteurs ayant un impact sur les scores ICC des étudiants universitaires tant au pays qu'à l'étranger et révélant des différences importantes entre les étudiants qui choisissent d'étudier à l'étranger et ceux qui ne le font pas. Les études à l'étranger semblent changer certains aspects de la CPI, mais pas tous. Un biais d'auto-sélection des étudiants peut rendre les changements ICC plus difficiles à documenter après des études à l'étranger. De plus, les activités sur le campus sont également liées au développement de I'ICC pour les étudiants universitaires. Lorsque les établissements d'enseignement supérieur cherchent à contribuer au développement de I'ICC chez leurs étudiants, étudier à l'étranger n'est pas la seule approche efficace et devrait donc être considéré comme un outil d'internationalisation de campus important parmi tant d'autres.

\section{Keywords:}

intercultural competence, higher education, university, study abroad

\section{Introduction}


Since the world today is a global stage, universities have a critical responsibility to prepare graduates who are ready to step into their roles as players in a globalized society. Vygotsky (1980) explains that culture is one of the lenses through which people view the world. Thus, a global worldview begins with the understanding of one's own culture and place in the world, being open-minded to learning about other cultures and using critical thinking to connect information learned about other cultures to one's own culture and immediate events. Having a solid knowledge foundation then enables college students to apply it in new intercultural contexts. Development of intercultural competence (ICC) for students is a lifelong progression, and universities should be key accelerants to the process. In the current study, we sought to determine whether the strategies employed at home and abroad utilized at a public doctoral institution 1) to foster ICC development for undergraduate students were actually doing so as intended and 2) to indicate a collective of effective internationalization strategies for institutions of higher education.

\section{Culture and Intercultural Competence}

Lindsey et al. (2003) define culture as an identity based on "shared views, history, and patterns of behaviors among persons, (as) culture is about groupness" (p. 41). Culture is an underpinning feature of a stable and wellfunctioning society. Culture is emergent. It does not fall from the sky and declare itself; it is brought about through human activity. Such activities and accepted views can be collectively recognized as norms, as norms are the shared values for what is acceptable within a community. The majority of people's views and behaviors are made up by cultural norms (Spitzberg, 2000). Likewise, many important factors of a culture help to shape the individuals within its bounds. Understanding what elements influence values and traits of a culture encourages people to take a more objective rather than a staunchly value-laden view of the world. Therefore, by understanding other cultures, people can better identify shared goals and values.

As the world continues to become increasingly interconnected, the concept of intercultural competence (ICC) becomes even more important and relevant. ICC is the knowledge of one's own culture in conjunction with an understanding and openness towards learning about and engaging with other cultures (Deardorff, 2011). ICC models almost always indicate three main domains of development: Intrapersonal (also known as behavioral or skills), interpersonal (affective), and cognitive (knowledge) (see, for example, Braskamp et al., 2009; Mateev \& Mertz, 2014). Developing each of these areas is crucial to helping students refine their worldviews. Rust's (2015) definition of ICC emphasizes adaptation: an ability to apply and transfer learned skills. One example of such a skill is the ability to successfully communicate across cultural groups (Krajewski, 2011). The emotional interpersonal aspect of ICC is likewise 
important. Bennett (2010) explains that intercultural learning must foster empathy in students as opposed to merely increasing tolerance. A study conducted by Odağ et al. (2015) asked students their perspective about what was the most important domain within the development of ICC. The results showed that students found knowledge as well as the traits of tolerance and respect to be important and necessary components of ICC. Fantini's (2000) model presents three outcomes of ICC, including ability to develop and maintain relationships; to conduct effective, appropriate communication; and to successfully interact and cooperate with others. Braskamp and Engberg (2011) confer that that important outcomes of ICC include having a global perspective and being able to "engage in intercultural relationships and behave in (a) socially responsible (manner)” (p.1). In all three domains, ICC is a developmental process that is continually evolving over time across peoples' lifespan and personal experiences (Krajewski, 2011) - a process where universities can (and, we argue, should) aid growth while students are within their walls and living spaces.

\section{Importance of Intercultural Competence}

ICC is crucial for communities to grow and thrive. With today's diverse and global landscape, ICC is quickly becoming necessary for everyday living (Irving, 2010). Communities throughout the United States have seen increases in ethnic diversity over the years, a trend also reflected on college campuses (Holmes \& O’Neill, 2012; Spitzberg, 2000). ICC is particularly necessary for graduates seeking employment (Busch, 2009; Shaftel et al., 2007) and for success in the workplace as globalization of U.S. businesses and commerce continues to expand (Penbek et al., 2012; Shaftel et al., 2007). Taken together, there are many reasons that today's college students need to increase their ICC for their personal and professional growth and why campuses need to ramp up their internationalization and inclusive excellence efforts.

One important reason for fostering ICC development in college students is to make them more effective during interactions with other campus constituents, whether that is done at home or abroad. In regards to diversification on college campuses, a report released by the U.S. Department of State analyzing the most recent Institute of International Education (2019a) Open Doors Data for 2017-2018 shows that for the United States, there was a 2\% increase in U.S. students who studied abroad and a $1.5 \%$ increase in international students studying in the U.S. International students made up 5.5\% of the students in higher education institutions. The total number of international students in the United States was 1,094,792, with a majority (33\%) coming from China. The Open Doors Report also shows that for U.S. American students studying abroad, a majority of students studied in Europe (54\%), with top program locations including the United Kingdom, Italy, and Spain. Most students participated in study abroad programs during short-term programs 
(65\%, 8 weeks or less), with significantly fewer students in semester-long (33\%) or year-long programs (2\%). While COVID-19 will have certainly affected study abroad in 2019-2020 (data not yet released by IIE), these statistics speak to the ever-increasing internationalization of college campuses, the variety of intercultural experiences, and the importance of fostering ICC development in university students so they are effective communicators on campus and beyond.

\section{Intercultural Competence and Study Abroad: Programmatic Influences}

Study abroad experiences have been widely hailed and assumed as one of the best ways students can increase in their ICC during their years at college. The immersive element of such experiences (when present) can have an immediate impact on students as they adjust to the different settings, providing an opportunity to learn through direct engagement in a new cultural milieu (Niehaus \& Crain, 2013). In a recent review, Haas (2018) determined that study abroad consistently shows impacts on students' cultural awareness. Study abroad programs often draw great interest by students; some even take study abroad into consideration when choosing which college to attend. Perhaps until COVID-19, continued and growing interest among students to study abroad existed, as the Open Doors data above demonstrate. However, is it simply being away from home that increases ICC? Not necessarily. Rust (2015) examined the impact of an embedded intercultural experience through a one-week study away program. Students $(N=3,500)$ were placed in one of three conditions. While all groups took a 16-week course, two of the groups also participated in the week-long study away program, with one of the groups' program being specifically designed to address intercultural awareness. Rust found significant differences before and after the experience only between the groups in the first (course without a study away) and third conditions (course with ICC awareness based study away). Such results speak to the importance of how an experience is developed, suggesting that programs that are geared towards fostering ICC for students will be more impactful than programs without a design that specifically addresses ICC.

When study abroad programs are designed well and rigorously, they can certainly have an impact on students' ICC development. What is also plausible, however, is that a pre-existing bias of students to study abroad already makes them think they are already more competent - even before studying abroad. While limited research in study abroad has measured changes in student development before and after programs, very few studies have looked at students' study abroad intentions or expectations as a predictive factor. One such study by Stebleton et al. (2013) proposed that purposes of study abroad programs, as well as students' expectations of those programs, can impact the 
likelihood of students developing in their ICC from programmatic influences. Stebleton et al. examined five different types of study abroad programs ranging from university-led to recreational travel. They found that the less structured and purposeful the program, the less positively it impacted students' ICC. This finding was especially true for the interpersonal domain, as students in the less structured programs were less likely to engage voluntarily with the host population. Stebleton et al. conclude that factors affecting study abroad and ICC have not been parsed out in most studies to the extent their study did, including how the types of study abroad opportunities that are available to students and how differing programs impact ICC. Their work highlights the importance of well-structured study abroad workshops from which students can have planned opportunities for development and engagement with host nationals. The importance of structure in study abroad programs is supported by both Pekenpaugh (2012) and Wiese and Wickline (2014), who specifically addressed the importance of the role of the instructor in leading students in meaningful activities and integrative experiences that bolster ICC while in the host country. Thus, if a study abroad is to be designed and executed - it ought to be done rigorously, thoughtfully, and purposefully. Unfortunately, not all study abroad programs take such a strategic approach. If study abroad programs are done poorly, students might actually learn and develop more on campus than they might while on a glorified travel excursion abroad.

In their review of literature, Vande Berg et al. (2012) propose that some of the most crucial elements of effective study abroad programs include continual learning throughout the experience. This includes both pre-departure courses that build a foundational knowledge base of cultural awareness for students, as well as reflective work upon return. Niehaus and Crain (2011), in their study comparing student experiences of service-learning abroad or domestically, found that students who participated in domestic service-learning scores reported less frequent engagement and reflection than did students in international programs. Similarly, a study conducted by Spenader and Retka (2015) found that students in study abroad workshops that incorporated servicelearning had higher ICC scores than those who were in workshops without a service-learning component, highlighting the importance of experiential learning. The concept of learning through experience is also supported by Stevens et al. (2015) in their discussion of ways in which to overcome cognitive and behavioral barriers to ICC growth. Taken together, study abroad programs benefit students when they include strategic engagement with members of the host culture.

\section{Intercultural Competence and Choosing Study Abroad: Student}

\section{Factors}


Realistically, even though study abroad can be very impactful upon students' growth, not all students can or will choose to participate in it. Characteristics or differences in the students themselves can influence whether or not they even consider studying abroad. For example, Goldstein and Kim (2006) focused on predictors that influenced students' decisions to study abroad such as foreign language acquisition, prior experience abroad, and expectations of a study abroad experience. The more positive their expectations, the more likely students were to study abroad. However, neither foreign language fluency nor prior travel experience were found to be important predictors. Anderson and Lawton (2015) also explored potential motivations for study abroad and how the study abroad experience impact students' ICC. Their study focused on the relative changes in ICC for study abroad students as reflected by pre-post scores on the Global Perspectives Inventory (GPI; Research Institute for Studies in Education, 2017). Interestingly, their study did not find any significant changes in ICC scores overall. However, they did find that motivations were related to ICC scores: Students who were motivated mainly by the entertainment value of studying abroad indicated lower ICC scores, while those who were motivated by factors other than entertainment (such as learning and growth) indicated higher ICC scores.

Although there are undoubtedly many potential benefits to studying abroad, there are also real, powerful, and numerous circumstances that bar students from taking the opportunity to study abroad. These include cost, distance, family obligations, job restrictions, financial limitations, and time restraints (see, for example, Goldstein, 2019). Timing (when a study abroad is offered during a year) and program duration are two of the main obstacles for study abroad participation (Kurt et al., 2013). Many institutions have taken note of this and now offer an array of study abroad options (Institute for International Education, 2019a), including full-semester, short-term or partial semester programs, as well as other opportunities to volunteer or partake in global internship programs (Stebleton et al., 2013). Indeed, short-term study abroad programs of a few weeks are becoming highly favored options for college students (Nguyen, 2017). Having programs of different lengths, however, does not remove all of the barriers to study abroad for all students that exist in addition to time constraints. Thus, for students who still are unable to, unwilling to, or disinterested in study abroad, campuses need to get creative at home.

\section{Influencing ICC on U.S. College Campuses}

Taken altogether, our review has shown that study abroad is one effective tool that institutions of higher education have to impact students' ICC, although the extent of the influence largely depends on the structure of the workshop, engagement willingness of students, and preparation by the program 
leader. Impediments to study abroad or study away participation must be taken into account by universities. The consideration of what can be done on campus to increase ICC is becoming an important topic of discussion for professors and administrators alike. As such, a growing body of literature examines what college campuses can and should do to increase ICC in more place-bound and time-strapped students (Soria \& Troisi, 2014). Co-curricular and extra-curricular activities such as service-learning, community service, and opportunities for engagement with other cultures while in the same country, state, and even city are shown to impact ICC (e.g., Wickline et al., 2016). Bennett (2010) writes "when appropriate facilitation of (service learning) experience(s) (takes place) ... these programs have the potential to generate significant, transferrable intercultural learning” (p.14). In one example, Borden (2007) found that students who engaged in service-learning for a semester decreased in their self-reported levels of ethnocentrism.

Beyond extra-curricular and co-curricular opportunities, promotion and development of ICC at home can also be achieved though integration of ICC within the college curriculum. For example, Mak (2012) examined the effectiveness of embedding ICC skill workshops within a health psychology course. Using reflective journals to measure impact, analysis of qualitative data revealed themes that showed students increased in awareness and development of skills that had relevance to their future careers. When addressing the inclusion of ICC instruction within course or curriculum content or classroom instruction, Deardorff (2009) suggests bringing multiple viewpoints or diverse perspectives to an issue or topic. This approach not only allows students to learn from the knowledge and insight of others but also encourages critical thinking and evaluation of one's own views in comparison to other views being presented. Taken together, these studies show the myriad benefits that oncampus programs and curriculum can have on students ICC.

\section{A Case Study in ICC: Miami University}

Miami University, in addition to offering a variety of study abroad options for students, is a public doctoral institution committed to fostering ICC development for students and faculty. This commitment is stated in Foundation Goal 2 of the Miami 2020 Plan, indicating that Miami aims to "promote a diverse culture of inclusion, integrity and collaboration that deepens understanding and embraces intercultural and Global experiences" (Miami University, 2013, p.4). The Ohio Fact Sheet from Institute for International Education (2019b) reported that in 2018, Miami's Oxford campus had 2,921 international students, ranking $4^{\text {th }}$ in the state for all Ohio institutions. The university offers more than 350 different co-sponsored study abroad workshops to over 90 countries. Nationally, Miami also ranks $3^{\text {rd }}$ in the nation among public doctoral institutions 
for number of undergraduate students studying abroad, with nearly $55 \%$ of students having participated in study abroad during their undergraduate years (Miami University, 2018). In addition to study abroad opportunities, Miami promotes ICC through its Global Courses (G-Courses). Throughout their time at Miami, students are required to take either six study abroad credit hours or six G-Course hours, which are "specially designed to have a global perspective and help students develop the ability to communicate and act respectfully across linguistic and cultural differences” (Miami University, 2019-2020, par. 7). Lastly, Miami has many community connections and classes that incorporate servicelearning during the semester. In 2018-2019, over 5,000 students at Miami completed over 40,000 hours of community service (Miami University, 2018). Clearly, ICC development for students is valued by the university. The question, however, remains: What kind of influence are Miami University's internationalization strategies having on students' ICC development?

\section{Goals of the Current Study}

The current study aimed to evaluate the impacts of study abroad programs, global courses, and co-curricular and extracurricular activities at a public doctoral institution on students' ICC scores. Our research generally explored whether students who studied abroad differed in ICC from students who did not study abroad; whether students' intent to study abroad impacted their ICC scores; and whether extracurricular and co-curricular activities and rate of engagement were related to ICC scores in G-course students. We proposed four specific hypotheses. Given the literature showing the viability of study abroad to affect ICC development, we proposed our first two hypotheses.

H1: Students who study abroad may differ in self-reported ICC from students who take G-courses both before and after the course or study abroad experience, indicating a self-selection bias for study abroad programs (using non-matched data).

H2: Students will increase in their self-reported levels of ICC after partaking in a Global Course or a study abroad workshop, as compared to their own scores before (using a sub-sample of matched data).

Next, because not all students intend to study abroad, we investigated the possibility of a self-selection bias also influencing students' ICC scores.

H3: Students who indicate no intent to study abroad will self-report lower ICC scores than either students who intended to study abroad or those who reported already having studied abroad.

Lastly, recognizing that ICC development does not start and stop in a brief time abroad or away, we explored the connections between ICC and other internationalization strategies. 
H4: Students who more often engage in co-curricular as well as extracurricular activities that foster ICC will also have higher self-reported ICC scores than students who indicate less frequent engagement in such activities.

\section{Method}

\section{Participants}

Our study consisted of 1,692 undergraduate students from both a main (highly residential) campus and a small (all commuter) campus. Of those students, 1,261 were enrolled in a one-semester global course, and 431 were part one of a wide variety of semester-long study abroad programs. In total (pre- and post-test demographics), the average age of participants was $20.56(S D=3.65)$. There were more women $(1,011)$ than men $(672)$. A majority of students $(1,069)$ grew up in the suburbs. Most identified as Caucasian American/White $(1,382)$, followed by Asian/Pacific Islander (94), African American/Black (64), multiple ethnicities (49), Hispanic/Latino(a) (29), and Native America (11). The overall average grade point average (GPA) was $3.25(S D=.47)$, and the median family income was $\$ 100,000$.

The pretest measures were completed by 1,113 students, with more respondents were in the global course (682) than in study abroad (431). As in the overall sample, there were more women (688) than men (422) with a majority identifying as White/Caucasian American (915), followed by Asian/Pacific Islander (59), African American/Black (36), multiple ethnicities (36), Hispanic/Latino(a) (18), and Native America (7). There was an average age of $20.51(S D=3.65)$, an average GPA of $3.24(S D=.47)$, and a median family income of $\$ 100,000$. In both groups, a majority of students reported residing in the suburbs (697). In the pretest, 244 students were in their first year, 273 were sophomores, 346 were in their junior year, and 198 were seniors.

For the Global Course students, pre-test $(n=682)$ demographics showed they had more women (371) than men (310), a reported median family income of $\$ 100,000$ and an average age of 20.31 years $(S D=3.37)$. For this group, 187 students were in their first year, 161 were sophomores, 200 were juniors, and 102 students were seniors. The average GPA for these students was $3.18(S D=.47)$ A majority of these students (536) reported being White/Caucasian American, followed by Asian/Pacific Islander (52), African American/Black (32), multiple ethnicities (24), Hispanic/Latino(a) (15), and Native America (2).

For the study abroad students $(n=431)$, 88\% reported being White/Caucasian (379), followed by multiple ethnicities (15), Asian American/Pacific Islander (7), Native American (5), African American/Black (4), Hispanic/Latino(a) (3). There was an average age of $20.83(S D=3.72)$. A majority 
of participants in this group were sophomores (123 or 29\%) or juniors (131 or $30 \%$ ). Similar to the global course students, there was a larger number of women (317) than men (112), with a mean GPA of 3.41(SD =.42) and a median family income of $\$ 100,000$. Please see Table 1 for a comprehensive demographic information.

Table 1. Pre-Test Demographics: Study Abroad and Global Course Students

\begin{tabular}{cccccc}
\hline Statistic & Age & GPA & $\begin{array}{c}\text { Mother's } \\
\text { Education }\end{array}$ & $\begin{array}{c}\text { Father's } \\
\text { Education }\end{array}$ & Income \\
\hline Mean & 20.51 & 3.24 & 5.51 & 5.83 & $\$ 1,401,804.31$ \\
Median & 20.00 & 3.30 & 6.00 & 6.00 & $\$ 100,000.00$ \\
Mode & 20.00 & 3.00 & 6.00 & 6.00 & $\$ 100,000.00$ \\
Std. Deviation & 3.51 & 0.47 & 1.52 & 1.77 & $\$ 35,023,662.49$ \\
Minimum & 0.00 & 0.58 & 0.00 & 0.00 & $\$ 10.00$ \\
Maximum & 66.00 & 4.00 & 9.00 & 9.00 & $\$ 100,000,000$ \\
$N$ & 1106 & 903 & 1113 & 1111 & 815 \\
\hline
\end{tabular}

\section{Measures}

\section{The Global Perspectives Inventory (GPI)}

To measure students' ICC, we used the Global Perspectives Inventory (GPI; Research Institute for Studies in Education, 2017), Version 5 and Version 7. During the years of our data collection, the GPI was being updated. Therefore, students who studied abroad took the GPI Version 5, as data collection with this group began in 2010 when Version 5 was published. Students in the one semester G-course were administered the GPI Version 7, as their data collection began in 2012, shortly after Version 7 - the most recent GPI version - was released.

Figure 1. Overview of the Global Perspectives Inventory (GPI) Theoretical Model*

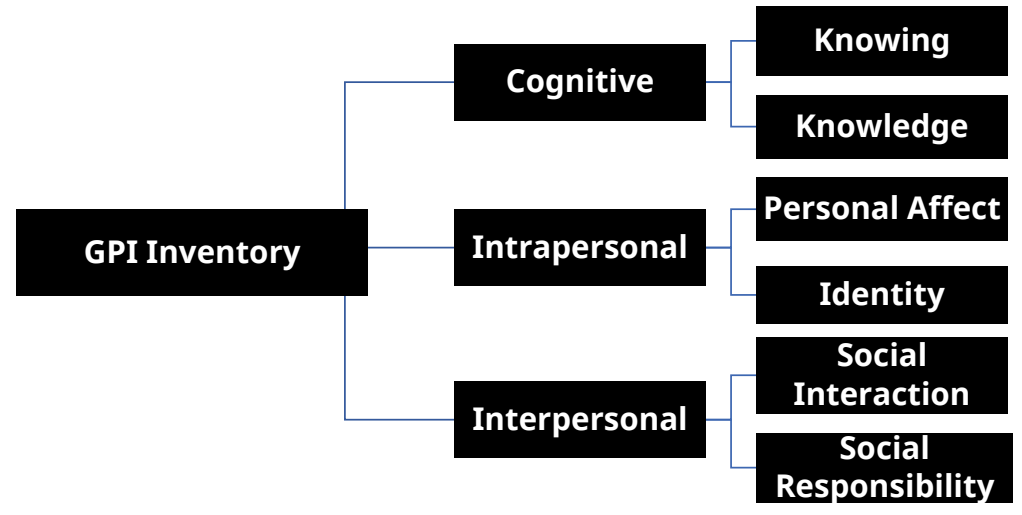


*Note. The Global Perspectives Inventory (GPI) is a self-reporting survey that measures students' global competency in three different domains: Cognitive, Intrapersonal and Interpersonal (Braskamp \& Engberg, 2011). Within each domain, there are two subdomains. The subdomains include: Knowledge, Knowing, Identity, Affect, Social Interaction and Social Responsibility. Knowledge and Knowing are measured in the Cognitive domain, Identity and Affect are measured in the Intrapersonal domain and social responsibility and interactions are measured in the Interpersonal domain.

The current and final form of the GPI (Version 7) is a self-report survey of 35 items that measures students' levels of intercultural competence with primary three domains: Cognitive, Intrapersonal, and Interpersonal (Research Institute for Studies in Education, 2017). Of the 35 core items, 32 are scored. The Cognitive domain includes the subdomains Knowing (understanding cultural context; 7 items) and Knowledge (awareness of cultural differences; 5 items). The Intrapersonal domain includes the subdomains Identity (sense of purpose and personal identity; 6 items) and Personal Affect (emotional awareness and acceptance of differences; 5 items). The Interpersonal domain includes the subdomains of Social Interaction (engaging sensitively with others; 4 items) and Social Responsibility (concern for others; 5 items). See Figure 1 for a conceptual model of the domains and subdomains of the GPI.

All GPI items were self-reported and utilized a five-point Likert scale ranging from strongly disagree (1) to strongly agree (5). A total of 8 items were reverse scored so that higher scores indicate greater competence. For the purposes of standardizing the tests across the two versions of the GPI, we kept only the items that were the same for both versions of the GPI (see Table 2, column 2). The reliability scores for our samples - three of which are sufficient, $(\alpha \geq .70)$, two of which are questionable $(.60 \leq \alpha \leq .70)$, and one of which is very low $(\alpha \leq .60)$ - were lower than the alpha levels for Version 7 produced by the measure's authors (Research Institute for Studies in Education, 2017). However, they were similar to reliabilities reported by Anderson and Lawton (2015).

Table 2. Global Perspectives Inventory (GPI) Reliability for Items Consistent Across Versions 5 and 7

\begin{tabular}{lccc}
\hline GPI Item & $\begin{array}{c}\text { Items with Different } \\
\text { Wording Across Versions }\end{array}$ & $\begin{array}{c}\text { Items with Identical } \\
\text { Wording Across Versions }\end{array}$ & $\begin{array}{c}\text { Cronbach's } \\
\alpha\end{array}$ \\
\hline Knowing & 3 & 5 & 0.38 \\
Knowledge & 0 & 5 & 0.71 \\
Identity & 1 & 5 & 0.66 \\
Personal Affect & 0 & 8 & 0.69 \\
Social Interaction & 0 & 7 & 0.72 \\
Social Responsibility & 0 & 5 & 0.70 \\
\hline
\end{tabular}




\section{Other Measures}

Extracurricular activity data were analyzed only for the G-course students in the pre-test, as this included the larger sample of student respondents and utilized the most recent version of the GPI. GPI supplementary items that ask about participation in extra and co-curricular activities were analyzed for students in the G-courses only (Version 7), as the versions differed in how these questions were measured and worded. For example, Version 5 asked how often students participated in the listed activities, while Version 7 asked how many terms ( 0 to $5^{+}$) students engaged in the listed activities.

Demographic data were also collected for each group before and after their semester's experience. Demographic items included gender, ethnicity, age, year in college, parents' highest level of education, and annual family income.

\section{Procedure}

After receiving approval from the Institutional Review Board, all participants were recruited through a convenience sampling method. Students were not offered any incentives for participating in the survey, nor were they penalized for not completing the survey. All students provided informed consent and were debriefed.

For study-abroad students, the pre-departure and post-program surveys were linked online in a list from the study abroad office of "to do" items or requirements before and after studying abroad. Surveys were completed using the online survey tool Qualtrics.

For the G-Course students, the institution's Office of Liberal Education sent an email to G-course instructors requesting their help in surveying students at the beginning and end of the course. These surveys were administered on paper during a class session.

\section{Results}

$\mathrm{H} 1$ : Students who study abroad may differ in self-reported ICC from students who take G-courses both before and after the course or study abroad experience, indicating a self-selection bias for study abroad programs. (Non-Matched Data)

To test this hypothesis, we conducted a 2 (pre-test versus post-test) x 2 (study abroad versus G-course) x 6 (GPI subdomains) MANOVA followed by a series of independent $t$-tests to determine if there were significant differences overall for students before and/or after their experience in either a study abroad workshop or G-course (see Table 3). Our study largely confirms this hypothesis. We found significant interactions between the three factors, $F(5,777)=3.12, p<.01, \eta^{2}=.02$. 
Results for the follow-up independent samples $t$-tests revealed significant differences in both pre-and post-test scores for several of the GPI subdomains. Significant differences (2-tailed) between study abroad and G-course students were noted in pre-test scores for Knowing, $t(1,690)=4.63, p<.05$; Personal Affect, $t(1,690)=4.05, p<.05$; Social Interaction, $t(1,690)=4.09, p<.05$; and Social Responsibility, $t(1,690)=4.79, p<.05$. Significant differences were not noted for Knowledge, $t(1,690)=-1.27, p>.05$; or Identity, $t(1,690)=1.83 p>.05$.

For Post-Test scores, 2-tailed significant differences were noted for Knowing, $t(781)=4.39, p<.05$; Personal Affect, $t(781)=3.24, p<.05$; Social Interaction, $t(781)=5.48, p<.05$; Social Responsibility, $t(781)=2.92, p<.05$. Again, significant differences were not noted for Knowledge, $t(781)=-.835, p>.05$; or Identity, $t(781)=1.46, p>.05$.

Table 3. Average Global Perspectives Inventory (GPI) Scores (Non-Matched Data) Before and After a Study Abroad or Global Course (G-Course)

\begin{tabular}{ccccc}
\hline & \multicolumn{2}{c}{ Study Abroad } & \multicolumn{2}{c}{ G-Course } \\
GPI Item & Pre & Post & Pre & Post \\
\hline Knowing & 3.57 & 3.64 & 3.34 & 3.42 \\
Knowledge & 3.56 & 3.68 & 3.60 & 3.71 \\
Identity & 4.05 & 4.08 & 4.00 & 4.03 \\
Personal Affect & 3.79 & 3.80 & 3.69 & 3.70 \\
Social Interaction & 3.43 & 3.50 & 3.32 & 3.32 \\
Social Responsibility & 3.67 & 3.67 & 3.52 & 3.56 \\
\hline$n$ & 431 & 431 & 1,261 & 352 \\
\hline
\end{tabular}


Figure 2. Global Perspectives Inventory (GPI) Scores Before and After a Study Abroad (SA) or Global Course (G-Course)

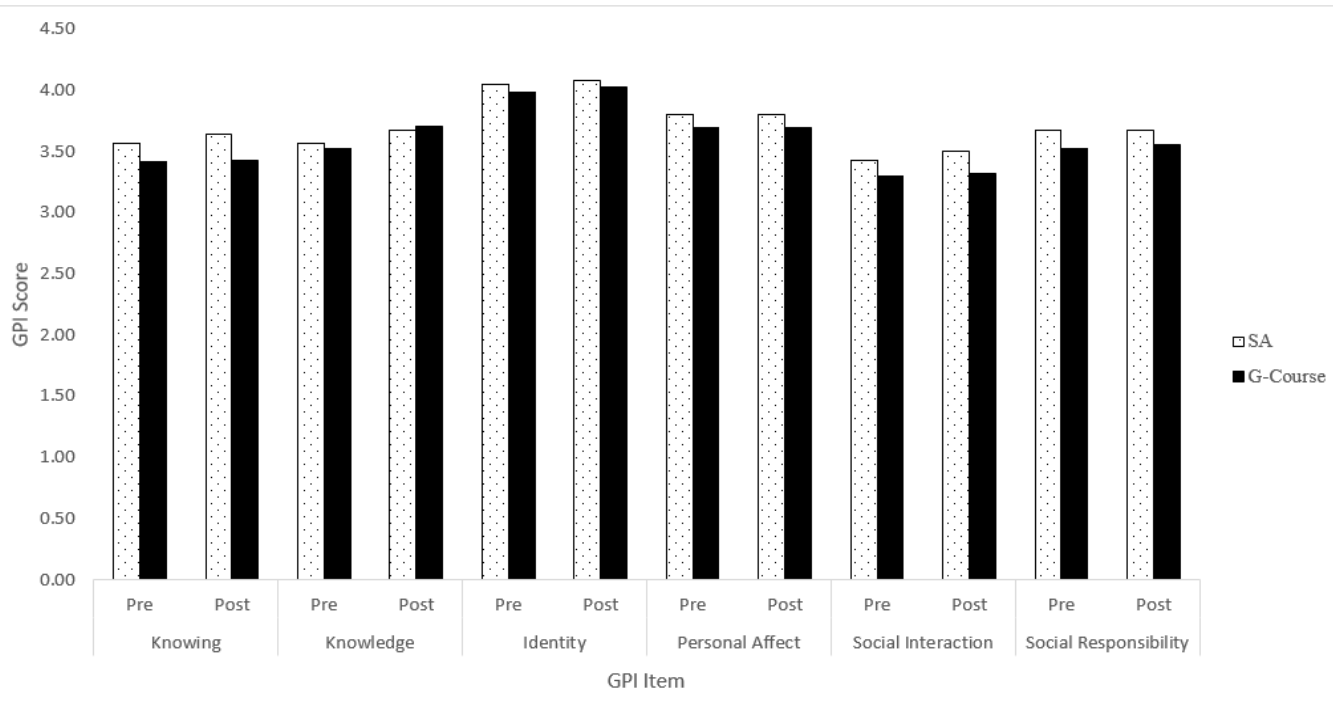

Note. Matched data ( $N=783$ total): Study Abroad $(n=431)$, G-Course $(n=352)$

In summary, we found that the ICC scores for students in the study abroad program and the students in the G-Course often, but not always, differed both at pre-test and at post-test. Study abroad students reported higher ICC scores in a majority of the six GPI items than did students in G-Courses both before and after their program (see Figure 2). This tends to suggest self-selection bias for study abroad programs, rather than program-specific effects.

H2: Students will increase in their self-reported levels of ICC after partaking in a Global Course or a study abroad workshop, as compared to their own scores before. (Sub-Sample, Matched Data)

To test this hypothesis, we used a 2 (course: study abroad or G-course) $\mathrm{x}$ 2 (time: Time 1 versus Time 2) x 6 (GPI subdomains) repeated measures MANOVA. Partial support was also evidenced for this hypothesis (see Table 4 for descriptive data). Many significant main effects and interactions were found for GPI items (see Table 5). First, significant main effects existed for GPI subdomain, $F(5,777)=333.34, p<.01$, Wilks $\lambda=.318$, and for Time (pre/post), $F(1,781)=$ $22.437, p<.01$, Wilks $1=.972$. A significant main interaction existed between GPI Subdomain and Course (study abroad/G-course), $F(5,777)=4.66, p<.01$, Wilks $\lambda$ $=.971$. Also, there was a significant main interaction effect between GPI subdomains and Time, $F(5,777)=12.08, p<.01$, Wilks $\lambda=.93$. There was not a significant interaction of Time and Course, $F(1,781)=22.437, p=.940$, Wilks $\lambda=$ 1.00. Lastly, there was a significant interaction between GPI subdomains, time, and course, $F(5,777)=3.121, p<.01$, Wilks $\lambda=.980$. 
Table 4. Average Global Perspectives Inventory (GPI) Scores (Matched Data) Before and After a Study Abroad or Global Course (G-Course)

\begin{tabular}{lcccc}
\hline & \multicolumn{3}{c}{ Study Abroad $(n=431)$} & G-Course $(n=352)$ \\
GPI Item & Pre & Post & Pre & Post \\
\hline Knowing & 3.57 & 3.64 & 3.42 & 3.42 \\
Knowledge & 3.56 & 3.68 & 3.52 & 3.71 \\
Identity & 4.05 & 4.08 & 3.98 & 4.03 \\
Personal Affect & 3.80 & 3.80 & 3.70 & 3.70 \\
Social Interaction & 3.43 & 3.50 & 3.30 & 3.32 \\
Social Responsibility & 3.67 & 3.67 & 3.53 & 3.56 \\
\hline
\end{tabular}

Note. Matched sample. ${ }^{*} p \leq .05$

Table 5. MANOVA Results for the Effects of Time and Course Type on Various Global Perspectives Inventory (GPI) Subdomain Scores

\begin{tabular}{|c|c|c|c|c|c|c|c|c|}
\hline Effect & $\begin{array}{c}\text { Test } \\
\text { Statistic }\end{array}$ & Value & $F$ & $\begin{array}{l}\text { Hyp } \\
\text { df }\end{array}$ & $\begin{array}{c}\text { Error } \\
\text { df }\end{array}$ & Sig. & $\begin{array}{c}\text { Partial } \\
\text { Eta } \\
\text { Squared }\end{array}$ & $\begin{array}{c}\text { Observed } \\
\text { Power }\end{array}$ \\
\hline $\begin{array}{l}\text { Test (Study Abroad/ } \\
\text { G-Course) }\end{array}$ & $\begin{array}{l}\text { Mean } \\
\text { Square }\end{array}$ & 26.40 & 22.44 & 1 & 781 & $<.001 *$ & 0.03 & 0.997 \\
\hline GPI subdomain & Wilks' $\wedge$ & 0.32 & 333.34 & 5 & 777 & $<.001 *$ & 0.68 & 1.000 \\
\hline GPI subdomain * Test & Wilks' $\wedge$ & 0.97 & 4.66 & 5 & 777 & $<.001 *$ & 0.03 & 0.976 \\
\hline Time (Pre/Post) & Wilks' $\wedge$ & 0.97 & 22.44 & 1 & 781 & $<.001 *$ & 0.03 & 0.997 \\
\hline $\begin{array}{l}\text { Time * Test } \\
\text { GPI subdomain * }\end{array}$ & Wilks' $\wedge$ & 1.00 & 0.01 & 1 & 781 & 0.94 & 0.00 & 0.051 \\
\hline $\begin{array}{l}\text { Time } \\
\text { GPI subdomain * }\end{array}$ & Wilks' $\wedge$ & 0.93 & 12.08 & 5 & 777 & $<.001 *$ & 0.07 & 1.000 \\
\hline Time * Test & Wilks' $\wedge$ & 0.98 & 3.12 & 5 & 777 & $<.001$ * & 0.02 & 0.879 \\
\hline
\end{tabular}

Note. Matched sample. ${ }^{*} p \leq .05$

\section{Follow-Up ANOVAS}

As a result of the significant interaction effects, we conducted a series of follow-up 2 (time) x 2 (course) one-way ANOVAS to assess each of the GPI subdomains separately. Significant ANOVAS included Knowledge and Social Interaction, while the remaining GPI subdomains (Knowing, Identity, Personal Affect and Social Responsibility) were not significant.

For Knowledge, we found that there was a significant main effect of time (pre/post), $F(1,781)=67.34, p<.05$, and a significant interaction between time and course (Study Abroad/G-Course) on Knowledge $F(1,781)=4.12, p<.05$. For Social Interaction, there was a significant main effect of time, $F(1,781)=10.19$, 
$p<.05$, and a significant effect of course type, $F(1,781)=25.85, p<.05$. Therefore, students in both groups increased in their knowledge and social interaction scores from pretest to posttest. The groups also significantly differed in social interaction scores; students in study abroad reported greater increases in this subdomain than did G-course students.

For the GPI subdomain of Knowing, while there was not a significant effect of time, $F(1,781)=.021, p>.05$, there was an effect of course type, $F(1,781)$ $=19.04 p<.05$. For the GPI subdomain of Identity, there was an effect of time, $F$ $(1,781)=7.11, p<.05$, but there was not an effect of course type, $F(1,781)=3.71$, $p>.05$. In Personal Affect, there was an effect of time, $F(1,781)=13.04, p<.05$, but not an effect of course type, $F(1,781)=.04, p>.05$. Lastly, for Social Responsibility there not an effect of time $F(1,781)=.857, p>.05$, but there was an effect of course type, $F(1,781)=13.39, p<.05$. These results suggest that students in both groups changed in their GPI scores before and after in the subdomains of Identity and Personal Affect, while there were significant differences between students in the study abroad workshop and G-courses in the subdomains of Knowing and Social Responsibility. While there were changes in scores for students in some subdomains, as seen in the effects of time, there were also differences between students in study abroad and G-courses, as reflected in the effects of course type. Therefore, while it is important to review the structure and impact of study abroad and courses on ICC, it is also important to note that there again appear to be pre-existing differences in students who choose to study abroad and those who do not.

H3: Students who indicate no intent to study abroad will self-report lower ICC scores than either students who intended to study abroad or those who reported already having studied abroad. (G-Course Students, Pre-Test Only)

To test this hypothesis, we used a 3 (study abroad) x 6 (GPI subdomains) MANOVA to assess the effects of intent to study abroad (do not intend, intend, already have) on the six GPI subdomains (Knowing, Knowledge, Identity, Personal Affect, Social Interaction and Social Responsibility). Overall, for students in G-courses, a majority reported no intent to study abroad (342, or 51\%) while 261 (39\%) expressed intent to study abroad and $71(10 \%)$ of the students reported having already studied abroad.

The results showed partial support for this hypothesis (please see Figure 3). A significant MANOVA was obtained: $F(5,667)=133.427, p<.001$, Wilks Lambda $(\mathrm{l})=.500$. Thus, a series of follow-up, one-way ANOVAs with post-hoc tests assessed differences in each of the GPI subdomains (see Table 6). The oneway ANOVA showed significant results at the .05 level for between groups in three of the six GPI subdomains including Knowledge, $F(2,671)=9.62, p<.05$; 
Social Interaction, $F(2,671)=6.61, p<.05$; and Social Responsibility, $F(2,671)=$ $3.22, p<.05$. There were not significant between group effects for Knowing $F(2$, $671)=.78, p>.05$; Identity, $F(2,671)=1.36, p>.05$; or Personal Affect, $F(2,671)=$ $1.71, p>.05$.

Figure 3. Study Abroad (SA) Intent and Global Perspectives Inventory (GPI) Subdomains

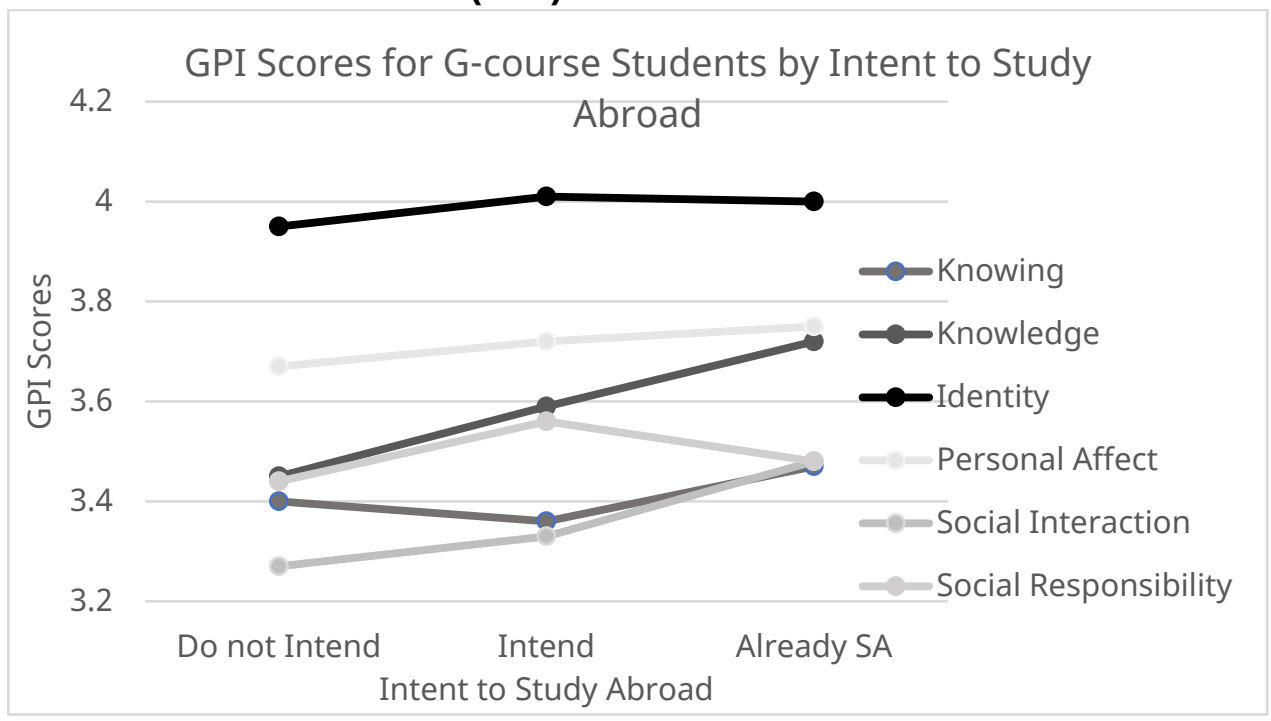

For the GPI subdomain of Knowledge, students who had no intent to study abroad $(M=3.44, S D=.57)$ reported significantly lower scores than either those who intended to study abroad $(M=3.58, S D=.54)$ or those who had already been abroad $(M=3.72, S D=.45)$, who did not significantly differ from each other. Thus, it appears a self-selection bias may exist for those who choose to study abroad, rather than the study abroad program itself having a significant impact.

In Social Interaction, students who had already studied abroad ( $M=3.48$, $S D=.36)$ reported significantly higher scores than students who either intended $(M=3.33, S D=.44)$ or did not intend $(M=3.27, S D=.46)$ to study abroad, which did not significantly differ from each other. Therefore, it appears the study abroad program had an influence on student's scores rather than there being a self-selection bias. 
Table 6. One-way ANOVA Analyses for Intent to Study Abroad and Global Perspectives Inventory (GPI) Scores for Students in Global Courses (G-Courses)

\begin{tabular}{|c|c|c|c|c|c|c|}
\hline Dependent Variable & $d f$ & $d f$ error & $F$ & Intent & Mean & $S D$ \\
\hline \multirow[t]{3}{*}{ Knowing } & 2 & 671 & 0.78 & Do Not Intend & 3.40 & 0.698 \\
\hline & & & & Intend & 3.36 & 0.677 \\
\hline & & & & Already SA & 3.46 & 0.731 \\
\hline \multirow[t]{3}{*}{ Knowledge } & 2 & 671 & $9.62 * *$ & Do Not Intend & 3.44 & 0.574 \\
\hline & & & & Intend & 3.58 & 0.537 \\
\hline & & & & Already SA & 3.72 & 0.449 \\
\hline \multirow[t]{3}{*}{ Identity } & 2 & 671 & 1.36 & Do Not Intend & 3.95 & 0.474 \\
\hline & & & & Intend & 4.01 & 0.420 \\
\hline & & & & Already SA & 4.00 & 0.415 \\
\hline \multirow[t]{3}{*}{ Personal Affect } & 2 & 671 & 1.71 & Do Not Intend & 3.67 & 0.426 \\
\hline & & & & Intend & 3.72 & 0.392 \\
\hline & & & & Already SA & 3.75 & 0.456 \\
\hline \multirow[t]{3}{*}{ Social Interaction } & 2 & 671 & $6.61 * *$ & Do Not Intend & 3.27 & 0.459 \\
\hline & & & & Intend & 3.33 & 0.438 \\
\hline & & & & Already SA & 3.48 & 0.360 \\
\hline \multirow[t]{3}{*}{ Social Responsibility } & 2 & 671 & $3.22 * *$ & Do Not Intend & 3.44 & 0.606 \\
\hline & & & & Intend & 3.56 & 0.516 \\
\hline & & & & Already SA & 3.48 & 0.604 \\
\hline
\end{tabular}

Notes. $* * p \leq .05$

Students in G-Course pretest scores only

For Social Responsibility, students who reported no intent to study abroad had significantly lower scores $(M=3.44, S D=.61)$ than students who intended to study abroad $(M=3.56, S D=.52)$, but not those who had already been abroad $(M=3.48, \mathrm{SD}=.60)$. Students who intended to go abroad or who had been abroad did not differ from each other. This pattern is not consistent with either a self-selection bias or programmatic impacts of study abroad. 
$\mathrm{H} 4$ : Students who more often engage in co-curricular as well as extracurricular activities that foster ICC will also have higher selfreported ICC scores than students who indicate less frequent engagement in such activities. (G-Course Students, Pre-Test Only)

To test this hypothesis, we used nonparametric, Spearman correlations since some of our variables (i.e., extra- and co-curricular activities) were ordinal, having asked students to report how often they have engaged in various activities while in college such as reading a newspaper, interacting with students from another country, and participating in leadership or team building activities. For all analyses, $672<N<682$. Please see Appendix A for a full correlation matrix. As hypothesized, more frequent exposure to these extracurricular and co-curricular activities positively correlated with students' self-reported ICC scores often. By Cohen's (1988) standards, a large number of small or moderate significant relationships were demonstrated. Overall, $76 \%$ of the correlations between these co-curricular and extracurricular activities and GPI scores were significantly, positively correlated (see Table 7).

The GPI subdomain Knowing had significant correlations with 7 of the 18 extracurricular items. Items that were most strongly correlated with this subdomain included the frequency of: reading a newspaper $r_{s}(680)=.23$; following an international event or crisis, $r_{s}(679)=.13$; interacting with students from a different race or ethnic group, $r_{s}(678)=.13$; participating in leadership activities that encouraged teamwork, $r_{s}(680)=.11$; participating in religious or spiritual activities, $r_{s}(680)=.11$; and attending campus events on global issues, $r_{s}(680)=.10$.

For the GPI subdomain of Knowledge, 16 of the 18 items were significantly correlated. Activities most strongly correlated included the frequency of: taking a world history course, $r_{s}(676)=.38$; taking a multicultural course, $r_{s}(679)=.36$; taking a course that focused on global or international issues, $r_{s}(677)=.25$, attending campus events on global issues, $r_{s}(680)=.22$; following international events, $r_{s}(679)=.22$; and discussing current events with other students, $r_{s}(679)=.21$.

The GPI subdomain of Identity was significantly correlated with 14 of the 18 items. Activities that were strongly correlated included the frequency of: taking a multicultural course, $r_{s}(679)=.21$; taking a foreign language course, $r_{s}(678)=.18$; taking a world history course, $r_{s}(676)=.15$; taking a servicelearning course, $r_{s}(672)=.15$; taking a course that focused on global issues, $r_{s}(677)$ $=.14$; and taking courses that allowed for dialogue among students with diverse backgrounds, $r_{s}(679)=.12$. 
Table 7. Extra-Curricular and Co-Curricular Activities Ordered by Counts of Significant Correlations with the Six Global Perspectives Inventory (GPI) Subdomains

\begin{tabular}{|c|c|}
\hline Activity & $\begin{array}{l}\text { Total Significant } \\
\text { GPI Correlations }\end{array}$ \\
\hline Participated in religious or spiritual activities & 6 \\
\hline Course focused on significant global/international issues and problems & 6 \\
\hline $\begin{array}{l}\text { Participated in events or activities sponsored by groups reflecting a cultural heritage } \\
\text { different from your own }\end{array}$ & 6 \\
\hline Interacted with students from a race/ethnic group different than your own & 5 \\
\hline Participated in leadership programs that stress collaboration and teamwork & 5 \\
\hline Read a newspaper or news magazine (online or in print) & 5 \\
\hline Attended a lecture//workshop/campus discussion on international/global issues & 5 \\
\hline Participated in community service activities & 5 \\
\hline $\begin{array}{l}\text { Course that includes opportunities for intensive dialogue among students with } \\
\text { different backgrounds and beliefs }\end{array}$ & 5 \\
\hline $\begin{array}{l}\text { Multicultural course addressing issues of race, ethnicity, gender, class, religion, or } \\
\text { sexual orientation }\end{array}$ & 5 \\
\hline Foreign language course & 5 \\
\hline $\begin{array}{l}\text { Followed an international event/crisis (e.g., through newspaper, social media, or } \\
\text { other media source) }\end{array}$ & 4 \\
\hline Service-learning course & 4 \\
\hline World history course & 4 \\
\hline Discussed current events with other students & 4 \\
\hline Interacted with students from a country different from your own & 3 \\
\hline $\begin{array}{l}\text { Participated in events or activities sponsored by groups reflecting your own cultural } \\
\text { heritage }\end{array}$ & 3 \\
\hline Watched news programs on television & 2 \\
\hline
\end{tabular}

Note. Significance include $p<.01$ and $p<.05$ levels. Sample included G-Course Students, Pre-Test GPI scores only.

The GPI subdomain of Personal Affect was significantly correlated with 15 of the 18 items. Activities most strongly correlated included the frequency of: attending religious or spiritual activities, $r_{s}(680)=.25$; taking a course that focused on global or international issues, $r_{s}(677)=.24$; taking a multicultural course, $r_{s}(679)=.22$; taking a world history course, $r_{s}(676)=.21$; reading a newspaper, $r_{s}(680)=.19$; and attending campus events on global issues, $r_{s}(680)$ $=.18$.

For the GPI subdomain of Social Interaction, 16 of the 18 items were significantly correlated. Activities most strongly correlated included the 
frequency of: attending campus events on global issues, $r_{s}(680)=.34$; participating in community service activities, $r_{s}(680)=.21$; interacting with students from a different race or ethnicity, $r_{s}(678)=.19$; and participating in leadership activities that encouraged teamwork, $r_{s}(680)=.18$.

For the GPI subdomain of Social Responsibility, 16 of the 18 items were significantly correlated. Activities most strongly correlated included the frequency of: Participating in community service, $r_{s}(680)=.32$; participating in religious or spiritual activities, $r_{s}(680)=.22$; attending events sponsored by groups from a different cultural heritage, $r_{s}(680)=.19$; attending a campus event on global issues, $r_{s}(680)=.16$; participating in leadership activities that encouraged teamwork, $r_{s}(680)=.16$; and taking a service-learning course, $r_{s}(672)$ $=.16$.

\section{Discussion}

\section{Limitations}

A number of limitations existed for this study. First, the data evaluated changes or comparison scores in one semester. It may very well be that the gains and benefits that come from intercultural learning take more time to unfold than the short-term window we observed. For example, Nguyen (2017) found when measuring ICC at three intervals - pre-test, post-test, and 3-months followup - that students continued to indicate gains in ICC months after a 2- to 5-week short-term study abroad workshop had ended.

The GPI measure itself presented some challenges. By incorporating two subsamples of students who had been administered different versions of the GPI while the measure itself was being finessed - thus drawing only on the identical items across the two versions and not all of the items from the current version of the GPI - we utilized the GPI in a different way than most researchers who would now use the current version (Version 7). Compiling data across differing versions of the GPI required us to eliminate some of the individual GPI items in order to have a uniform measure for both groups, and reliability statistics were somewhat questionable for some subdomains in our sample when compared to estimates presented by the publisher. Additionally, these ICC scores are selfreported: an indirect rather than direct measure of competence. Finally, our sample also included students from one large public university in the Midwest, whose demographics include relatively low numbers of domestic ethnic minority students and whose study abroad initiatives represent a large proportion of faculty-led, short-term study abroad programs, which may limit the generalizability of results.

\section{Summary of Key Findings}


Even with these limitations, our results provide evidence that study abroad is one very promising way to increase students' ICC, yet it is by no means the only important way. Self-selection biases also seem to impact ICC selfreported scores, which institutions will need to address during study abroad recruitment and researchers will want to consider when running study abroad analyses. Moreover, a variety of globally-connected or "glocal" (global issue, local focus) strategies also show promise as ways to aid student development.

First, our study found partial support for the hypothesis that students would increase in their ICC scores before and after a study abroad or G-course, especially when matched with their own scores. We found some but not all students' ICC subdomain scores increased after a semester-long intercultural learning experience, whether at home or abroad. Students from both types of courses significantly increased in Knowledge and Social Interaction, but Knowledge increases were higher for students on campus, while Social Interaction increases were higher for students abroad. Thus, study abroad may not be consistently or inherently "better" than on-campus programs. It could depend, in part, on whether the ICC development outcome goals for the program are more cognitive, affective, or behavioral and how well the program is designed and implemented. Similar results were obtained by Braskamp and Engberg (2011). This finding shows the need for further evaluations of study abroad programs and course content in terms of how to better address the remaining subdomains of ICC both abroad and at home.

Second, we found that students who choose to study abroad often had self-reported higher ICC scores than did students who did not intend to study abroad. This was consistent with Martin (1987). Specifically, the Martin study found that those with the most abroad experience scored themselves higher in intercultural abilities than students with no experience abroad. Our research showed that there were differences in some ICC scores for students who studied abroad and students who participated in a G-course for a semester both before and after a study abroad workshop or G-course. This result confirmed our hypothesis that students who do not choose to study abroad differ from students who do, even before they go abroad, suggesting a self-selection bias for study abroad programs. This hypothesis is consistent with the findings of Shaftel et al. (2007), as well as Goldstein and Kim (2005), whose studies also noted differences between students who do and do not choose to study abroad. More specifically, in our study, the students who studied abroad consistently reported higher scores than did students in the G-courses across many of the six GPI subdomains. This indicates that perceptions of one's competency levels may be influenced even by anticipation of the study abroad workshop (Anderson \& Lawton, 2015).

Lastly, we determined that there are many extracurricular and cocurricular activities that positively relate to students' self-reported ICC. The 
more often students partake in these globally-minded activities, the higher they tend to indicate their ICC. These findings were consistent with Soria and Troisi's (2014) study.

\section{Research and Practice Recommendations}

It is most certainly important to evaluate and develop study abroad programs with rigor and care, thus providing high potential for fostering ICC. However, it is also imperative to be mindful that while a study abroad program may be very well-developed and carried out, gains in ICC are subjective across students and are not necessarily always observed within the timeframe of a single intercultural experience. This will be especially true since students appear likely to be bringing a self-selection bias with them for study abroad programs. For future studies, longitudinal data collection of students' ICC scores should be conducted throughout and perhaps months or years after their college career in order to examine how college efforts collectively impacted students' ICC throughout a developmental process, sans an endpoint (Fantini, 2000). Fantini furthermore advocates for the assessment of ICC at various points throughout a study abroad experience, instead of only beginning and end, which could provide important and useful information for the analysis of programmatic impacts. Programs might also increase impacts by having students take a well-designed pre-departure and/or post-return course for academic credit (e.g., Goldstein, 2017).

Moreover, research on study abroad programs' effectiveness for ICC development should continue to compare short-term, semester, and year-long programs, as well as the overall structure of the programs, in order to determine how these characteristics have an effect. Certain programs may well attract specific subpopulations of students (Odağ et al., 2015). For example, as the study by Spenader and Retka (2015) showed that programs with language requirements may have students with greater knowledge of the culture and more confidence interacting due to their language skills. Also, measures of students' ICC should continue to be developed and refined, particularly in the aim of finding an effective measure that does not rely exclusively on student self-reporting, which can challenge validity due to self-perception biases. Perry and Southwell (2011), for example, suggest the use of reflective writing samples as an indicator of ICC in lieu of a standardized self-report inventory.

Keeping in mind the self-selection bias that was often found in the present study, where students who intended to study abroad already self-rated as higher on many ICC subdomains than those who did not intend to study abroad, it is imperative that institutions do not simply go after "low-hanging fruit" or "preach to the choir" by marketing their study abroad programs to students who are already open to the possibility. They must clear pathways and 
break down barriers to make study abroad a more realistic and viable option for those whom, for personal or practical reasons, do not initially envision themselves participating. This could include departmental support and institutional scholarships (to remove financial burdens for all but especially first-generation and limited income students), short-term and very short-term programs (to diversity their yield and particularly encourage more nontraditional student participation), and faculty-led options (for those students too timid or hesitant to go it alone).

Finally, if institutions really want to be the accelerant in their students ICC growth, they should not be hedging their bets and hanging their assessment fully and completely on the potential influence of one semester (or less) abroad or away. Özturgut et al. (2014), in their review of best practices for internationalizing college campuses, describe how study abroad needs to be one of many approaches if institutions are to internationalize effectively and increase the intercultural competence of students, faculty, and staff, an idea championed by many other authors (Braskamp \& Engberg, 2011; Sobania \& Braskamp, 2009; Stier, 2006; Stone, 2006; Volet, 2004). Institutions should be fueling the fire by investing in ICC opportunities not only around the globe but across the campus, throughout the curriculum, within the classroom, and in the community. On-campus elements like event programming, international student groups, international education weeks, globally-minded departmental and college-level curriculum revisions, and proper administrative program support are also crucial for college campus internationalization and student development efforts.

\section{References}

Anderson, P. H., \& Lawton, L. (2015). Student motivation to study abroad and their intercultural development. Frontiers: The Interdisciplinary Journal of Study Abroad, 26, 39-52. https://doi.org/10.36366/frontiers.v26i1.354

Bennett, M. (2010). A short conceptual history of intercultural learning in study abroad. In W. Hoffa \& S. Depaul (Eds.), A history of U.S. study abroad: 1965-present. Special publication of Frontiers: The Interdisciplinary Journal of Study Abroad (pp.419-449).

Borden, A. W. (2007). The impact of service-learning on ethnocentrism in an intercultural communication course. Journal of Experiential Education, 30(2), 171-183. https://doi.org/10.1177/105382590703000206

Braskamp, L. A., Braskamp, D. C., \& Merrill, K. (2009). Assessing progress in global learning and development of students with education abroad experiences. Frontiers: The Interdisciplinary Journal of Study Abroad, 18, 101-118. https://doi.org/10.36366/frontiers.v18i1.256

Braskamp, L. A., \& Engberg, M. E. (2011). How colleges can influence the development of a Global Perspective. Liberal Education, 97, 34-39. https://www.aacu.org/publicationsresearch/periodicals/how-colleges-can-influence-development-global-perspective

Busch, D. (2009). What kind of intercultural competence will contribute to students' future job employability? Intercultural Education, 20(5), 429-438. https://doi.org/10.1080/14675980903371290 
Cohen, J. (1988). Statistical power analyses for the social sciences. Lawrence Erlbaum Associates.

Deardorff, D. K. (2011). Assessing intercultural competence. New Directions for Institutional Research, 2011(149), 65-79. https://doi.org/10.1002/ir.381

Fantini, A. E. (2000). A central concern: Developing intercultural competence. SIT Occasional Paper Series: About Our Institution (p. 25-42). http://citeseerx.ist.psu.edu/viewdoc/download?doi=10.1.1.117.8512\&rep=rep1\&type= pdf

Goldstein, S. (2017). Teaching a psychology-based study abroad pre-departure course. Psychology Learning \& Teaching, 16(3), 404-424. https://doi.org/10.1177/1475725717718059

Goldstein, S. (2019). Support for a multidimensional model of study abroad immersion preference. Frontiers: The Interdisciplinary Journal of Study Abroad, 31(1), 1-21. https://doi.org/10.36366/frontiers.v31i1.440

Goldstein, S. B., \& Kim, R. I. (2006). Predictors of US college students' participation in study abroad programs: A longitudinal study. International Journal of Intercultural Relations, 30(4), 507-521. https://psycnet.apa.org/doi/10.1016/j.ijintrel.2005.10.001

Haas, B. W. (2018). The impact of study abroad on improved cultural awareness: A quantitative review. Journal of International Education, 29 (5-6), 571-588. https://doi.org/10.1080/14675986.2018.1495319

Holmes, P., \& O'Neill, G. (2012). Developing and evaluating intercultural competence: Ethnographies of intercultural encounters. International Journal of Intercultural Relations, 36(5), 707-718. https://psycnet.apa.org/doi/10.1016/j.ijintrel.2012.04.010

Institute of International Education. (2019a). 2018 "Fast facts." Open Doors Report on International Educational Exchange. https://www.iie.org/Research-andInsights/Open-Doors/Fact-Sheets-and-Infographics

Institute of International Education. (2019b). 2018 Fact sheet: Ohio. Open Doors Report on International Educational Exchange. https://www.iie.org/Research-andInsights/Open-Doors/Fact-Sheets-and-Infographics/Data-by-State-Fact-Sheets

Irving, J. A. (2010). Educating global leaders: Exploring intercultural competence in leadership education. Journal of International Business and Cultural Studies, 3, 1-14. http://www.aabri.com/manuscripts/09392.pdf

Krajewski, S. (2011). Developing intercultural competence in multilingual and multicultural student groups. International Education, 10(2), 137-153. https://doi.org/10.1177\%2F1475240911408563

Lindsey, R. B., Robins, K. N., \& Terrell, R. D. (2003). Cultural proficiency: A manual for school leaders. Corwin Press.

Mak, A. S. (2012). Embedding intercultural competence development in the psychology curriculum. Psychology Learning \& Teaching, 11(3), 365-369. https://doi.org/10.2304\%2Fplat.2012.11.3.365

Martin, J. N. (1987). The relationship between student sojourner perceptions of intercultural competencies and previous sojourn experience. International Journal of Intercultural Relations, 11(4), 337-355. https://doi.org/10.1016/S0147-1767(87)80002-0

Mateev, A. V., \& Merz, M. Y. (2014). Intercultural competence assessment: What are its key dimensions across assessment tools? In L. T. B. Jackson, D. Meiring, F. J. R. Van de Vijver, E. S. Idemoudia, \& W. K. Gabrenya Jr. (Eds.), Toward Sustainable Development Through Nurturing Diversity: Selected Papers from the Twenty-First Congress of the International Associate for Cross-Cultural Psychology (pp. 141-153). https://scholarworks.gvsu.edu/iaccp_papers/128/ 
Miami University (2019-2020). General bulletin 2019-2020. Miami University. http://bulletin.miamioh.edu/liberal-education/foundation-courses/

Miami University (2018). Report card 2018-2019. Miami University. https://miamioh.edu/ files/documents/about-miami/report-card-2018-2019 508.pdf

Niehaus, E., \& Crain, L. K. (2013). Act local or global? Comparing student experiences in domestic and international service-learning programs. Michigan Journal of Community Service Learning, 20(1), 31-40. http://hdl.handle.net/2027/spo.3239521.0020.103

Nguyen, A. (2017). Intercultural competence in short-term study abroad. Frontiers: The Interdisciplinary Journal of Study Abroad, 29(2), 109-127. https://doi.org/10.36366/frontiers.v29i2.396

Odağ, Ö., Wallin, H. R., \& Kedzior, K. K. (2015). Definition of intercultural competence according to undergraduate students at an international university in Germany. Journal of Studies in International Education, 1, 1-22. https://doi.org/10.1177\%2F1028315315587105

Özturgut, O., Cantu, M. P., Pereira, L. J., \& Ramón, D. K. (2014). Effective strategies in internationalization of higher education in the United States. International Journal of Research \& Studies in Education, 3(2), 29-39. http://consortiacademia.org/wpcontent/uploads/IJRSE/IJRSE v3i2/569-2450-1-PB.pdf

Penbek, Ş., Yurdakul Şahin, D., \& Cerit, A. G. (2012). Intercultural communication competence: A study about the intercultural sensitivity of university students based on their education and international experiences. International Journal of Logistics Systems and Management, 11(2), 232-252. https://doi.org/10.1504/IJLSM.2012.045425

Perry, L. B., \& Southwell, L. (2011). Developing intercultural understanding and skills: Models and approaches. Intercultural Education, 22(6), 453-466. https://doi.org/10.1080/14675986.2011.644948

Research Institute for Studies in Education (2017). Global Perspective Inventory: Scales and component items. Iowa State University. http://www.gpi.hs.iastate.edu/documents/2016\%20GPI\%20Scale\%20Report.pdf.

Rust, K. G. (2015). Exploring if an embedded study-away experience impacts change in undergraduate students' intercultural competence and awareness. Management, 3(3-4), 67-76. http://www.davidpublisher.org/Public/uploads/Contribute/556806b95ac26.pdf

Shaftel, J., Shaftel, T., \& Ahluwalia, R. (2007). International educational experience and intercultural competence. International Journal of Business \& Economics, 6(1), 25-34. http://assets.csom.umn.edu/assets/119235.pdf

Sobania, N., \& Braskamp, L. (2009). Study abroad or study away: It’s not merely semantics. Peer Review, 11(4). https://www.aacu.org/publications-research/periodicals/studyabroad-or-study-away-its-not-merely-semantics

Soria, K. M., \& Troisi, J. (2014). Internationalization at home alternatives to study abroad: Implications for students' development of global, international, and intercultural competencies. Journal of Studies in International Education, 18(3), 261-280. https://doi.org/10.1177\%2F1028315313496572

Spenader, A. J., \& Retka, P. (2015). The role of pedagogical variables in intercultural development: A study of faculty led programs. Frontiers: The Interdisciplinary Journal of Study Abroad, 25, 20-36. https://doi.org/10.36366/frontiers.v25i1.342

Spitzberg, B. H. (2000). A model of intercultural communication competence. Intercultural Communication: A Reader, 9, 375-387. 
http://www.communicationcache.com/uploads/1/0/8/8/10887248/a model of interc ultural communication competence.pdf

Stebleton, M. J., Soria, K. M., \& Cherney, B. T. (2013). The high impact of education abroad: College students' engagement in international experiences and the development of intercultural competencies. Frontiers: The Interdisciplinary Journal of Study Abroad, 22, 1-24. https://doi.org/10.36366/frontiers.v22i1.316

Stier, J. (2006). Internationalisation, intercultural communication and intercultural competence. Journal of Intercultural Communication, 11, 1-12. https://www.immi.se/intercultural/nr11/stier.pdf

Stevens, M. J., Fox-Kirk, W., Thompson, B. S., Fawcett, A. M., \& Fawcett, S. E. (2015). Developing intercultural competencies: Elaborating the personal barriers to change. Journal of Strategic Management Studies, 7(1), 19-34.

Stone, N. (2006) Conceptualising intercultural effectiveness for university teaching. Journal of Studies in International Education, 10(4), 334-356.

https://doi.org/10.1177\%2F1028315306287634

Vande Berg, M., Paige, R. M., \& Lou, K. H. (2012). Student learning abroad: What our students are learning, what they're not, and what we can do about it. Stylus Publishing, LLC.

Volet, S. (2004). Challenges of internationalisation: Enhancing intercultural competence and skills for critical reflection on the situated and non-neutral nature of knowledge. Language and Academic Skills in Higher Education, 6, 1-10. http://citeseerx.ist.psu.edu/viewdoc/download?doi=10.1.1.196.2361\&rep=rep1\&type= pdf

Vygotsky, L. (1980). Mind in society: The development of higher psychological processes. Harvard University Press.

Wickline, V.B., Matthews, S., Davis, H. L., \& Ferguson, Ch. (2016). Exploring intercultural competence with non-traditional students: A case study at Miami University (Ohio). Conference Proceedings of the Hawaiian International Conference on Education. http://hiceeducation.org/wp-content/uploads/proceedings-library/EDU2016.pdf

Wiese, D., \& Wickline, V. B. (2014). Considering the full package: Attention and detail in a short-term study abroad program. International Psychology Bulletin, 18(4), 29-31. http://div52.net/wp-content/uploads/2020/06/IPB 2014-18-4-FALL.pdf

\section{Author Biographies}

Virginia B. (Ginger) Wickline, PhD, is an Assistant Professor of Psychology at Georgia Southern University. She has over 20 years of experience studying cultural adjustment and intercultural competence of U.S. domestic college students, study abroad students, and international students. She has co-led study abroad programs in Scotland, England, and Japan.

Allie M. Shea, BA (International Studies and Psychology) has presented research on cultural adjustment/intercultural competence at national conferences and to Congressional delegates on Capitol Hill. Currently, she is an Institute of World Politics graduate student and also works for the Office of Administration for the Executive Office of the President.

Cheryl D. Young, PhD, is Assistant Provost for Global Initiatives at Miami University. Young's educational background is in English Literature, Women's 
Studies, and Educational Leadership, Curriculum, and Culture. Her current research projects are based in the currere framework method and curiosity as an intercultural competence cultivated in sojourn experience.

Deborah Wiese, PhD, is an Associate Clinical Professor in the Psychology Department at Miami University. Wiese's research focuses on the development of cultural competence, exploring pedagogical strategies and other factors that increase cultural competence in students. Her research also addresses psychological well-being, social support, and cultural immersion in international relocation. 


\section{Appendix A: Spearman Correlation of Extracurricular and Co-Curricular Activities and Global Perspectives Inventory (GPI) Subdomains*}

\begin{tabular}{|c|c|c|c|c|c|c|c|c|c|c|c|c|c|c|c|c|c|c|c|c|c|c|c|c|}
\hline Variable & 1 & 2 & 3 & 4 & 5 & 6 & 7 & 8 & 9 & 10 & 11 & 12 & 13 & 14 & 15 & 16 & 17 & 18 & 19 & 20 & 21 & 22 & 23 & 24 \\
\hline GPI 1 & - & $-.066^{*}$ & $-.071^{*}$ & $278^{* *}$ & $.152^{\star \star *}$ & $.108 * *$ & $.225 * *$ & $.125 * \star$ & .011 & -0.061 & $.132^{* *}$ & $.108 * *$ & $.084^{\star}$ & $.087 *$ & -0.008 & .051 & .051 & .033 & $.101^{* *}$ & $-.067 *$ & .036 & .033 & $.092 * *$ & $.106^{* *}$ \\
\hline GPI 2 & & - & $.344 * *$ & $.294 * *$ & $.376 * *$ & $.155^{* *}$ & $.088 *$ & $.092 * *$ & $.188^{* * *}$ & $.075^{*}$ & $.216 * *$ & $.189 * *$ & $.125 * *$ & $.173^{* *}$ & $-.069 *$ & .072 & .054 & $.182 * *$ & $.220 * *$ & $.211 * *$ & $.379 * *$ & $.358^{* *}$ & $.246 * *$ & $.187^{* *}$ \\
\hline GPI 3 & & & & $.350 * *$ & $.187^{* *}$ & $.294^{* *}$ & .074 & .029 & .060 & . 073 & .062 & .099** & $.121 * *$ & $.104^{\star *}$ & $.120 * *$ & $.179 * *$ & $.148^{* *}$ & $.089 * *$ & $.087^{\star}$ & .060 & $.150 * *$ & $.207 * *$ & $.136 * *$ & $.100 * *$ \\
\hline GPI 4 & & & & - & $.432 * *$ & $.289 * *$ & $.187^{* *}$ & $.123^{* *}$ & .071 & . 021 & $.142 * *$ & $.158^{* *}$ & .060 & $.144^{* *}$ & .003 & $.067 *$ & .111 ** & $.080^{*}$ & $.176 * *$ & $.114^{* *}$ & $.205 * *$ & $.221 * *$ & $.235 * *$ & $.248 * *$ \\
\hline GPI 5 & & & & & - & $.362 * *$ & $.166^{* *}$ & $.185^{* *}$ & $.085 *$ & .054 & $.140^{* *}$ & $.180 * *$ & $.161 * *$ & $.344 * *$ & .057 & $.096 * *$ & .171 ** & $.212^{* *}$ & $.152^{* *}$ & .065 & $.136 * *$ & $.148 * *$ & $.341^{* *}$ & $.343 * *$ \\
\hline GPI 6 & & & & & & & .054 & $.090^{* *}$ & -057 & $.157 * *$ & -.018 & .033 & $.101 * *$ & $.185^{\star *}$ & $.215^{* *}$ & $.156 * *$ & $.324 * *$ & $.157^{* *}$ & .019 & -.004 & .015 & $.071 *$ & $.103^{* *}$ & $.092 * *$ \\
\hline 7 & & & & & & & - & $.229 * *$ & $.332 * *$ & $.230 * *$ & $.483^{* *}$ & $.476^{* *}$ & $.161 * *$ & $.244 * *$ & $.089 *$ & $.223 * *$ & $.185 * *$ & $.253^{* *}$ & $.161 * *$ & .032 & $.094 * *$ & $.136 * *$ & $.224 * *$ & .186 ** \\
\hline 8 & & & & & & & & - & $.181 * *$ & .042 & $.215^{* *}$ & $.224 * *$ & $.085 *$ & $.194 * *$ & $.089 * *$ & $.137 * *$ & $.119 * *$ & $.134 * *$ & $.125 * *$ & .048 & $.084 *$ & $.122 * *$ & $.192 * *$ & $.141^{* *}$ \\
\hline 9 & & & & & & & & & - & $.280 * *$ & $.393 * *$ & $.286 * *$ & .057 & $.133^{* *}$ & $.079 *$ & $.095 * *$ & .061 & $.128^{* *}$ & $.154^{* *}$ & $.123 * *$ & $.129 * *$ & $.167 * *$ & $.103^{* *}$ & $.116^{* *}$ \\
\hline 10 & & & & & & & & & & - & $.248 * *$ & $.281 * *$ & $.099 * *$ & $.145^{* *}$ & $.115^{* *}$ & $.129 * *$ & $.226 * *$ & $.129 * *$ & .012 & 0.029 & -0.045 & $.072^{*}$ & .054 & .016 \\
\hline 11 & & & & & & & & & & & - & $.537 * *$ & $.192 * *$ & $.246^{* *}$ & $.083 *$ & $.187 * *$ & $.156^{* *}$ & $.318^{* *}$ & $.178^{* *}$ & $.115^{* *}$ & $.203 * *$ & $.222 * *$ & $.173 * *$ & $.119 * *$ \\
\hline 12 & & & & & & & & & & & & & $.203^{* *}$ & $.295^{\star *}$ & $.101 * *$ & $.239 * *$ & $.192 * *$ & $.245^{* *}$ & $.209^{* *}$ & $.105^{* *}$ & $.158^{* *}$ & $.175 * *$ & $.201 * *$ & $.185^{* *}$ \\
\hline 13 & & & & & & & & & & & & & - & $.560 * *$ & $.255 * *$ & $.347 * *$ & $.341 * *$ & $.304 * *$ & $.161 * *$ & $.085 *$ & $.122 * *$ & $.158 * *$ & $.295 * *$ & $.200 * *$ \\
\hline 14 & & & & & & & & & & & & & & . & $.262 * *$ & $.376 * *$ & $.429 * *$ & $.436^{* *}$ & $.162^{* *}$ & $.113^{* *}$ & $.140^{* *}$ & $.198^{* *}$ & $.387 * *$ & $.306^{* *}$ \\
\hline 15 & & & & & & & & & & & & & & & - & $.361 * *$ & $.341 * *$ & $.155^{* *}$ & $.093^{* *}$ & .055 & .044 & $.075 *$ & $.140 * *$ & $.084 *$ \\
\hline 16 & & & & & & & & & & & & & & & & 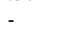 & $.549 * *$ & $.287 * *$ & $.197 * *$ & $.119 * *$ & $.155 * *$ & $.250 * *$ & $.204 * *$ & .182 ** \\
\hline 17 & & & & & & & & & & & & & & & & & & $.296^{* *}$ & $.158^{* *}$ & $.150^{* *}$ & $.095 * *$ & $.165 * *$ & $.194 * *$ & $.162^{* *}$ \\
\hline 18 & & & & & & & & & & & & & & & & & & & $.200^{* *}$ & $.188^{* *}$ & $.215^{* *}$ & $.253^{* *}$ & $.260 * *$ & $.155^{* *}$ \\
\hline 19 & & & & & & & & & & & & & & & & & & & 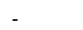 & $.574^{\star *}$ & $.586 * *$ & $.444 * *$ & $.254^{* *}$ & $.288 * *$ \\
\hline 20 & & & & & & & & & & & & & & & & & & & & 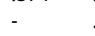 & $.606 * *$ & $.436^{* *}$ & $.153^{* *}$ & $.172^{* * *}$ \\
\hline 21 & & & & & & & & & & & & & & & & & & & & & . & $.610 * *$ & $.260 * *$ & $.259 * *$ \\
\hline 22 & & & & & & & & & & & & & & & & & & & & & & - & $.338 * *$ & $.349 * *$ \\
\hline 23 & & & & & & & & & & & & & & & & & & & & & & & & .691 ** \\
\hline \multirow[t]{8}{*}{24} & & & & & & & & & & & & & & & & & & & & & & & & \\
\hline & & & ariable & & Mean & SD & & $\begin{array}{l}\text { Variable } \\
\end{array}$ & & Mean & SD & & & riable & & Mean & SD & & Varic & able & & Mean & SD & \\
\hline & & GPI - Kno & wing & & 3.39 & 0.69 & 7. Multicul & Itural Cos & urse & 1.51 & 1.36 & 13. & Event Eth & nicity Ow & & 2.23 & 1.18 & 19. $\mathrm{Re}$ & ead News & & & 3.41 & 1.12 & \\
\hline & & GPI - Kno & wledge & & 3.53 & 0.55 & 8. Foreign & Languag & ge Course & 1.36 & 1.48 & 14. & Event Eth & nicity Oth & & 2.09 & 1.02 & 20. W & atch Nen & & & 3.22 & 1.16 & \\
\hline & & GPI - Ide & tity & & 3.98 & 0.45 & 9. World H & History $\mathrm{Co}$ & purse & 1.09 & 1.06 & $5 \quad 15$. & Event Rel & gious/Sp & jiritual & 2.18 & 1.33 & 21. Fo & dllow Glot & bal Crisis & & 3.36 & 1.13 & \\
\hline & & GPI - Per & SAffect & & 3.70 & 0.42 & 10. Service & e Learnin & g Course & 0.46 & 0.81 & 16. & Event Col & laboratio & & 2.60 & 1.30 & 22. $\mathrm{Di}$ & scuss Cri & & & 3.39 & 1.00 & \\
\hline & & GPI - Soc & al Interaction & & 3.31 & 0.44 & 11. Global & issues & & 1.29 & 1.28 & 317. & Event Cor & nmunity & Service & 2.55 & 1.20 & 23. In & teract wit & th Own Ra & & 3.13 & 1.05 & \\
\hline & & GPI - Soc & al Responsibilit & & 3.49 & 0.57 & 12. Dialog & & & 1.31 & 1.48 & 18. & Discuss $\mathrm{G}$ & lobal Isst & & 2.20 & 1.06 & 24. In & teract wit & th Other R & Race & 3.42 & 1.02 & \\
\hline
\end{tabular}

*Notes. For all analyses $672<N<682 . *=p<.05 * *=p<.01$

GPI = Global Perspectives Inventory. All GPI items scored from 1 (Strongly Disagree) to 5 (Strongly Agree). All other items asked about co-curricular and extracurricular activities, asking "How often in college did you..." and were scored from 1 (never) to 5 (very often). $7=$ Take a multicultural course. $8=$ Take a world history course, 9 = Take a service-learning course. 10 = Take a course that discussed global issues. $12=$ Course allowing for dialogue among diverse groups of students. $13=$ Attend event of own ethnicity. $14=$ Attend event of other ethnicity. $15=$ Attend religious or spiritual events. $16=$ Attend event encouraging collaboration/teamwork. $17=$ Attend community service event. $18=$ Discuss global events with other students. $19=$ Read news in print or online. $20=$ Watch news on television. 21 = Follow a global crisis. $22=$ Discuss global crisis with peers. $23=$ Interact with students of own race. $24=$ Interact with students of different race 